\title{
Term gravid uterus in a congenital umbilical hernia: a case report
}

\author{
Friday Saidi ${ }^{1,3^{*}} \mathbb{0}$, Bakari Rajab ${ }^{2,3}$, Lameck Chinula ${ }^{1,3,4}$, Nomsa Kafumba ${ }^{3}$, Maganizo Chagomerana ${ }^{1}$ and \\ Jennifer H. Tang ${ }^{1,4}$
}

\begin{abstract}
Background: Umbilical hernias are a frequent and well-known pathology in children or adults. Congenital umbilical hernias are commonly diagnosed in childhood, and in adulthood such a hernia is usually acquired. Umbilical hernia in pregnancy may result in serious obstetric complications including antepartum hemorrhage, intrauterine fetal demise, and preterm labor, particularly if incarcerated.

Case presentation: We present a rare case of a congenital umbilical hernia in a term pregnancy. The patient was a 34-year-old African (Malawian) woman, living with human immunodeficiency virus (HIV) and on antiretroviral treatment, gravida 4, with three previous vaginal deliveries, and with two babies weighing $4 \mathrm{~kg}$ at birth. We performed herniorrhaphy at caesarean section, and at 3 months of follow-up she had no evidence of a recurrent hernia.

Conclusion: Congenital umbilical hernias are commonly diagnosed in childhood but might first be seen by medical practitioners in adulthood. A patient-centered approach addressing patient complaints, associated risk factors, and possible complications is recommended. Primary repair at caesarean section is a feasible option.
\end{abstract}

Keywords: Congenital umbilical hernia, Pregnancy, Herniorrhaphy

\section{Background}

Umbilical hernias are a frequent and well-known pathology in children and adults. Congenital umbilical hernias are commonly diagnosed in childhood, and in adulthood such a hernia is usually acquired. Umbilical hernias in pregnancy may result in serious obstetric complications including antepartum hemorrhage, intrauterine fetal demise, and preterm labor, particularly if incarcerated [1-3]. We report a rare case of a congenital umbilical hernia in a term pregnancy for which herniorrhaphy was performed at the time of cesarean section, with a positive outcome.

*Correspondence: fsaidi@unclilongwe.org

1 University of North Carolina Project-Malawi, P. Bag A-104, Lilongwe, Malawi

Full list of author information is available at the end of the article

\section{Case presentation}

A 34-year-old African (Malawian) woman, gravida 4, para 3, living with human immunodeficiency virus (HIV) and on antiretroviral treatment, presented to the antenatal clinic at 31 weeks gestation with an umbilical hernia that was noted since birth. She presented with a 3-day history of fever, generalized body pain, and 4-week history of a dragging sensation in the abdomen and episodes of abdominal discomfort.

She had three previous spontaneous vaginal deliveries with the previous two pregnancies, birth weight of $4.3 \mathrm{~kg}$ and $4.4 \mathrm{~kg}$, with no prior screening for gestational diabetes. All three previous pregnancies were herniated pregnancies with no notable obstetric complications. The past gynecological and surgical history were unremarkable.

On physical examination, the patient was febrile and tachycardic. Abdominal examination revealed an umbilical hernia about $25 \mathrm{~cm} \times 20 \mathrm{~cm}$ with the anterior abdominal wall hanging down and extending downwards up to original author(s) and the source, provide a link to the Creative Commons licence, and indicate if changes were made. The images or other third party material in this article are included in the article's Creative Commons licence, unless indicated otherwise in a credit line to the material. If material is not included in the article's Creative Commons licence and your intended use is not permitted by statutory regulation or exceeds the permitted use, you will need to obtain permission directly from the copyright holder. To view a copy of this licence, visit http://creativecommons.org/licenses/by/4.0/. The Creative Commons Public Domain Dedication waiver (http://creativeco mmons.org/publicdomain/zero/1.0/) applies to the data made available in this article, unless otherwise stated in a credit line to the data. 


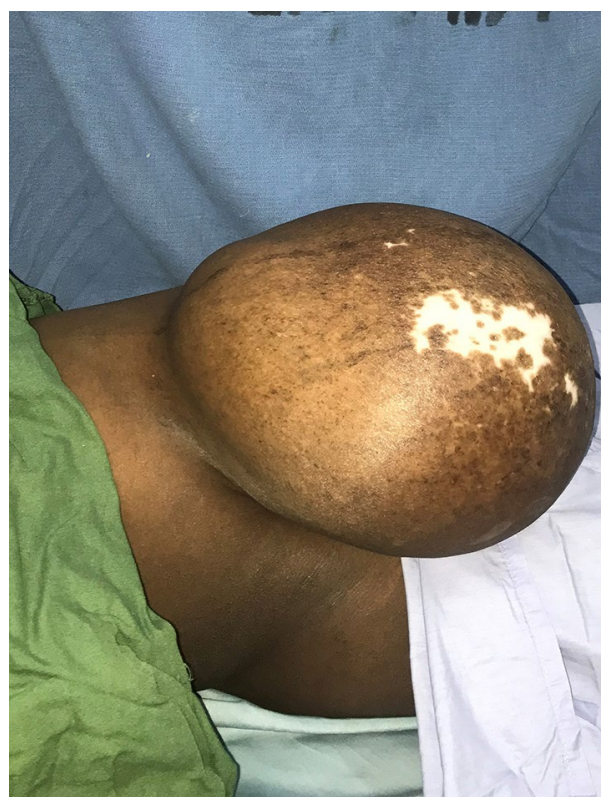

Fig. 1 Herniated term pregnancy

the mid-thigh (Fig. 1). A 32-week-size gravid uterus was palpable and the anterior abdominal wall was not reducible. The uterus and bowels were felt through the wall. There was also a well-healed skin ulcer on the anterior abdominal wall (Fig. 2).

Obstetric ultrasound showed gravid uterus herniated in the umbilical hernia leading to some limitations of the scan. Otherwise, the scan revealed a 31-week live single fetus in longitudinal lie with a fundal-anterior placenta, estimated fetal weight of $1800 \mathrm{~g}$, and adequate fluid volume.

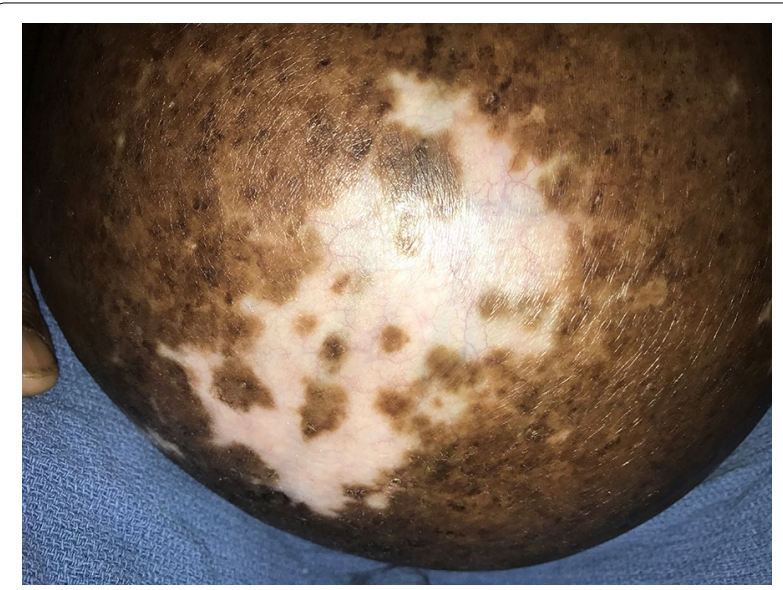

Fig. 2 Healed ulcer on the anterior abdominal wall
The patient was diagnosed with malaria, confirmed by malaria rapid diagnostic test, admitted to the antenatal ward, given lumefantrine-artemether (four tablets twice daily for 3 days) for malaria, and recovered very well. She was given dexamethasone for fetal lung maturation to mitigate the potential risk of respiratory distress if any preterm delivery occurred. After the patient recovered from the malaria, the pregnancy progressed uneventfully to term. The patient was counseled on the mode of delivery and contraception. She opted for a permanent method of contraception and noted that she preferred to undergo a scheduled surgery for cesarean, bilateral tubal ligation, and herniorrhaphy at 39 weeks. She preferred this plan to the alternatives of waiting for labor and ending up with a potential unscheduled cesarean and tubal ligation without appropriate staffing for herniorrhaphy, or having a vaginal delivery and then encounter delays with scheduling a postpartum tubal ligation with herniorrhaphy. Therefore, with the patient's consent, caesarean section and bilateral tubal ligation, along with herniorrhaphy at the time of caesarean section, were performed at 39 weeks of gestation.

The abdomen was opened by supra-umbilical vertical incision. The hernia sac was incised; the gravid uterus was lying in the sac and was exteriorized prior to the delivery of the baby (Fig. 3). A transverse lower uterine segment incision was made, and we extracted a live full-term female infant weighing $3.7 \mathrm{~kg}$ with APGAR scores of 9 and 10 at 1 and 5 minutes, respectively. The infant was also noted to have an umbilical hernia at the

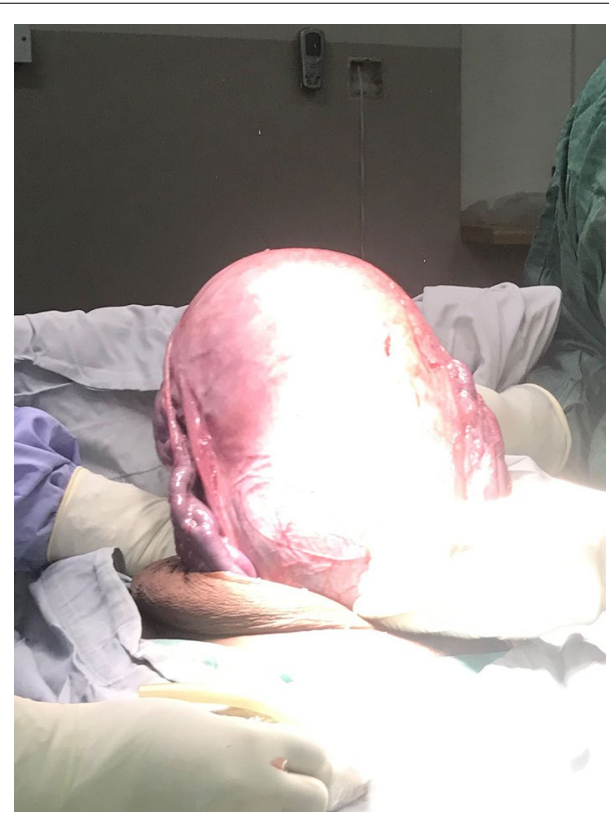

Fig. 3 Exteriorized uterus prior to extraction of the baby 


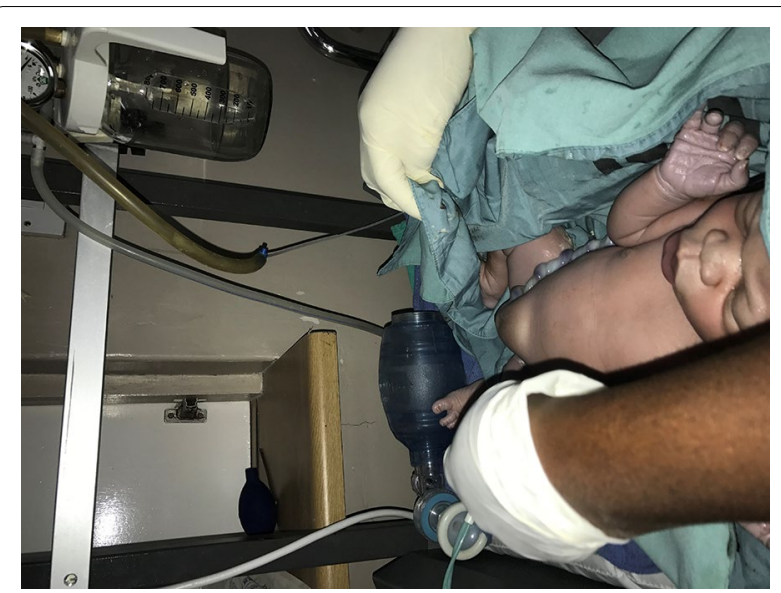

Fig. 4 The newborn with congenital umbilical hernia

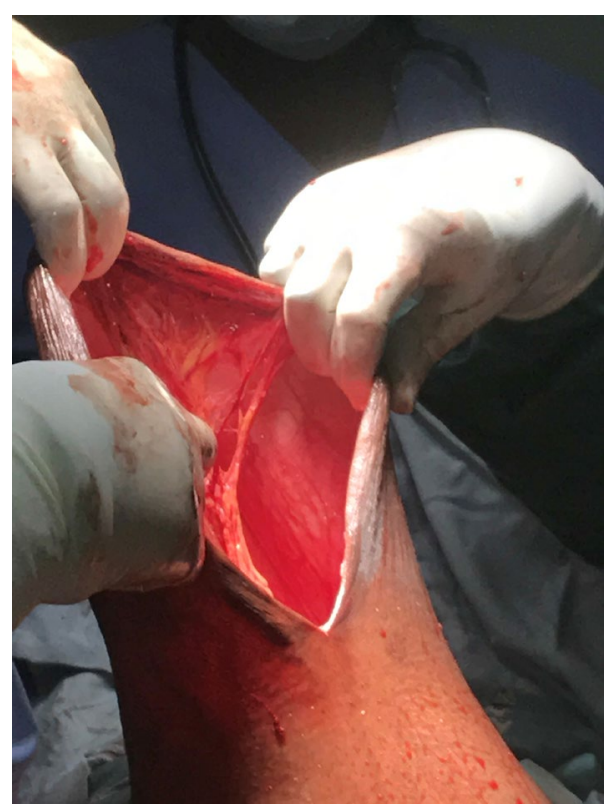

Fig. 5 Excision of redundant skin

time of birth (Fig. 4). After a bilateral tubal ligation was performed, the uterus was replaced in its normal pelvic position. Herniorrhaphy was performed with a running locking suture after excision of the hernia sac. Redundant skin and subcutaneous tissue were excised and the skin was sutured (Fig. 5).

The patient had an uneventful postoperative period and was discharged on day 4, and her stitches were removed on day 10. Our repair was still intact at the 3-month follow-up, with no evidence of herniation, and the patient was satisfied with the outcome. The infant was referred to the pediatricians for follow-up for the congenital umbilical hernia.

\section{Discussion}

Umbilical hernia is common among African populations, with an estimated prevalence as high as 15\% among pregnant women in West Africa [4]. Most umbilical hernias in adulthood are congenital and date back to childhood [5]. We reported a case of congenital umbilical hernia diagnosed first in pregnancy. Herniation of a gravid uterus in an umbilical hernia is rare because the gravid uterus is usually too large to enter the umbilical sac by the time it reaches the level of the hernia orifice [6].

There are sporadic reports of herniation of a gravid uterus through the anterior abdominal wall, and these are largely case reports. Most of the reported umbilical hernias in pregnancy were incisional hernias [7-10], and a few were congenital umbilical hernias $[5,11]$. None of these cases reported an outcome of the baby also having a congenital umbilical hernia, as was the case with our patient.

Herniation during pregnancy in the umbilical sac may result in serious maternal and fetal complications. These include ulceration of the skin overlying the hernia, as was seen in our patient. Other reported obstetric complications that may result in maternal and neonatal morbidity include preterm labor, antepartum hemorrhage, rupture of the lower uterine segment, abnormal labor, postpartum hemorrhage, intrauterine growth restriction, and intrauterine fetal demise [6, 7].

Normal vaginal delivery has been accomplished in pregnant patients with the umbilical hernia and uterus lying within a hernia [3]. Our patient had three previous uneventful vaginal deliveries, with two of her babies weighing more than $4 \mathrm{~kg}$ each at birth. For our case, we opted for herniorrhaphy at the time of elective caesarean section, and we achieved a successful operative outcome. Controversy exists in the management of umbilical hernia in pregnancy due to the lack of literature describing the best evidence-based approach. Some authors recommend postpartum elective herniorrhaphy because the overstretched abdominal wall may interfere with wound repair and result in wound disruption or high infection rates [12]. However, others have performed herniorrhaphy at the time of caesarean section with a successful outcome, as in our case $[9,11,13]$. The use of mesh is another recommended option for repair of the hernia $[11,14]$. We did not use a mesh for our patient because meshes are not available even when strongly indicated in our setting. 


\section{Conclusion}

Management of a patient with a gravid uterus in an umbilical hernia requires a patient-centered approach addressing patient complaints and possible complications. Knowledge of all possible complications and their unusual presentations can help achieve successful pregnancy and operative outcomes. Primary repair of an umbilical hernia at caesarean section is a feasible option.

\section{Acknowledgements}

Not applicable.

\section{Authors' contributions}

FS, BR, and NK managed the case, compiled the manuscript, and revised and edited the manuscript. LC, JT, and MC critically revised and edited the manuscript. All authors read and approved the final manuscript.

\section{Funding}

There is no external funding to declare.

\section{Availability of data and materials}

Not applicable.

\section{Declarations}

Ethics approval and consent to participate

Not required.

\section{Consent for publication}

Written informed consent was obtained from the patient for publication of this case report and any accompanying images. A copy of the written consent is available for review by the Editor-in-Chief of this journal.

\section{Competing interests}

The authors have no competing interests to declare.

\section{Author details}

1 University of North Carolina Project-Malawi, P. Bag A-104, Lilongwe, Malawi. 2 Department of Obstetrics and Gynecology, Baylor College of Medicine, Houston, USA. ${ }^{3}$ Department of Obstetrics and Gynecology, Kamuzu Central Hospital, Lilongwe, Malawi. ${ }^{4}$ Department of Obstetrics and Gynecology, University of North Carolina, Chapel Hill, NC, USA.

Received: 8 January 2021 Accepted: 23 February 2021

Published online: 03 April 2021

\section{References}

1. Dasgupta S. Incisional hernia in pregnancy. Int J User-Driven Healthc. 2013:2(4):60-2.

2. Karunavathi GPN, Shravya T. Evisceration of gravid uterus in anterior abdominal wall defect with scar rupture: a case report. Medicine. 2015;14(1):36-7.

3. Nagpal MKS. Herniated pregnant uterus with bleeding from previous abdominal scar. J Obs Gynaecol India. 2003;53:283.

4. Meier D, OlaOlorun D, Omodele R, Sunday TJ. Incidence of umbilical hernia in African children: redefinition of "normal" and reevaluation of indications for repair. World J Surg. 2001;25(5):645-8.

5. Adesiyun AG, Ameh N, Umar-sullyman H, Avidime S. Term gravid uterus as a content of congenital umbilical hernia-a complication in a multigravida that presented in labour. Case Rep Clin Med. 2015;1:6-9.

6. Banerjee N, Deka D, Sinha A, Prasrad RTD. Gravid uterus in an incisional hernia. J Obs Gynaecol Res. 2001;27:77-9.

7. Kanhere AV, Nandmer GK, Mhaske A. Case Report Gravid uterus in an incisional hernia with uterine scar dehiscence: a case report. Int J Reprod. 2013;2(4):674-6.

8. Chaudhuri S, Mitra SN, Daga A, Bandopadhyay D. Gravid uterus in an anterior abdominal wall hernia and successful repair at the. Case Rep. 2009;2(4):57-8.

9. Makama JG, Odigie VI, Yusufu LMD, Ameh N. Gravid uterus: clinical course and result of treatment. Herniated. 2007;6(4):197-9.

10. Achuri A, Achanta $V$, Arikarevula S. A rare case of herniation of gravid uterus. Case Report. 2012;2:10-3.

11. Punguyire $D$, Iserson $K V$, Apanga S. Full-term pregnancy in umbilical hernia. Pan Afr Med J. 2011;8:1-6.

12. Adesunkami ARFB. Incidence and aetiological factors of incisional hernia in a post caesarian operation in a Nigerian hospital. J Obs Gynaecol. 2003:23:258-60.

13. Malhotra M, Sharma JB, Wadhwa LAR. Successful pregnancy outcome after caesarian section in a case of gravid uterus growing in an incisional hernia of the anterior abdominal wall. Indian J Med Sci. 2003;57:501-3.

14. Israelsson LA, Smedberg S, Montgomery A, Nordin PSL. Incisional hernia repair in Sweden. Hernia. 2000;10:258-61.

\section{Publisher's Note}

Springer Nature remains neutral with regard to jurisdictional claims in published maps and institutional affiliations.
Ready to submit your research? Choose BMC and benefit from:

- fast, convenient online submission

- thorough peer review by experienced researchers in your field

- rapid publication on acceptance

- support for research data, including large and complex data types

- gold Open Access which fosters wider collaboration and increased citations

- maximum visibility for your research: over $100 \mathrm{M}$ website views per year

At $\mathrm{BMC}$, research is always in progress.

Learn more biomedcentral.com/submissions 